\title{
Clinical Characteristics and Manifestations of Fungal Esophagitis: A Single-Center Experience in South China
}

\author{
Shu-Kai Zhan $(\mathbb{D}$, Xiao-Qin Wu, and Feng-Ping Zheng $\mathbb{D}$ \\ Department of Gastroenterology, The Third Affiliated Hospital of Sun Yat-Sen University, Guangzhou, China \\ Correspondence should be addressed to Feng-Ping Zheng; zhengfp@mail.sysu.edu.cn
}

Received 24 August 2020; Revised 22 December 2020; Accepted 5 January 2021; Published 18 January 2021

Academic Editor: Fabiana Zingone

Copyright (C) 2021 Shu-Kai Zhan et al. This is an open access article distributed under the Creative Commons Attribution License, which permits unrestricted use, distribution, and reproduction in any medium, provided the original work is properly cited.

\begin{abstract}
Fungal esophagitis is a common infectious disease, although the pathogenic clinical characteristics remain incompletely clear, especially in South China. The goal of this study was to investigate the pathogenic clinical characteristics of fungal esophagitis and the efficacy of different therapeutic strategies at a tertiary hospital in South China. A retrospective study was conducted from January 2007 to December 2017. Data from 113,390 patients who were treated in the endoscopic unit were retrieved and analyzed. To further understand the pathogen and risk factors for fungal esophagitis, we performed a case-control analysis of 101 patients and 202 controls. Of the 113,390 patients, $932(0.82 \%)$ were positive. The annual detection rate ranged from $0.345 \%$ to $1.106 \%$, showing an initially increasing and subsequently decreasing trend. The patients' median age was 49 years (range from 8 to 85$)$, and most were men $(615 / 932,65.99 \%)$. Candida albicans was found in samples collected from 36 patients, without any drug-resistant strains. Age $(P=0.018)$, malignancy $(\mathrm{OR}=4.031,95 \% \mathrm{CI}: 1.562 \sim 10.407)$, cigarette smoking $(\mathrm{OR}=3.017,95 \% \mathrm{CI}: 1.645 \sim 5.533)$, and the use of antibiotics $(\mathrm{OR}=2.178,95 \% \mathrm{CI}: 1.078 \sim 4.400)$ or immunosuppressants $(\mathrm{OR}=6.525,95 \% \mathrm{CI}: 1.089 \sim 39.105)$ were independently associated with esophageal candidiasis. Fluconazole had a better curative effect than nystatin $(\mathrm{OR}=4.047,95 \% \mathrm{CI}$ : $1.282 \sim 12.772)$ or simple observation (OR $=8.91,95 \%$ CI: 2.61 30.49). In conclusion, fungal esophagitis primarily affects men and elderly individuals; it develops in the setting of malignancy, smoking, and certain previous medication use. Candida albicans is the most common pathogen and is sensitive to antifungal agents. Fluconazole has a good therapeutic effect.
\end{abstract}

\section{Introduction}

Fungal esophagitis (FE) is an infectious disease caused by fungi adhering to and invading the epithelial cells of the esophagus [1]. As a result, white plaques, which are observable during gastroscopy, appear on the esophageal surface. Reports have shown that severe FE may cause esophageal hemorrhage, stricture or fistula formation, or even fungalassociated septicemia, accompanied by reduced quality of life and high mortality (approximately 20\%-49\%) in severe situations $[2,3]$. A variety of symptoms including heartburn, acid regurgitation, nausea, dysphagia, and odynophagia have been reported to predict esophagitis, but which symptoms can predict FE remains unclear. The clinical presentations are nonspecific, and it is sometimes difficult to clinically or radiologically distinguish FE from other gastroenterological, cardiac, or neurologic diseases [4-7]. The risk factors for the development of FE in immunocompetent patients have not been entirely elucidated. In today's rapidly aging society, with the westernization of lifestyles and the widespread use of proton pump inhibitors (PPIs) and immunosuppressive agents, the pathogenic and epidemiological characteristics might vary. Studies on long-term trends of FE prevalence in South China have been very limited to date [8-11].

Therefore, in the present study, we report the results of a large, endoscopy-based, retrospective study and a casecontrol study aimed at investigating the epidemiology, clinical features, therapeutic interventions, and outcomes associated with FE. 


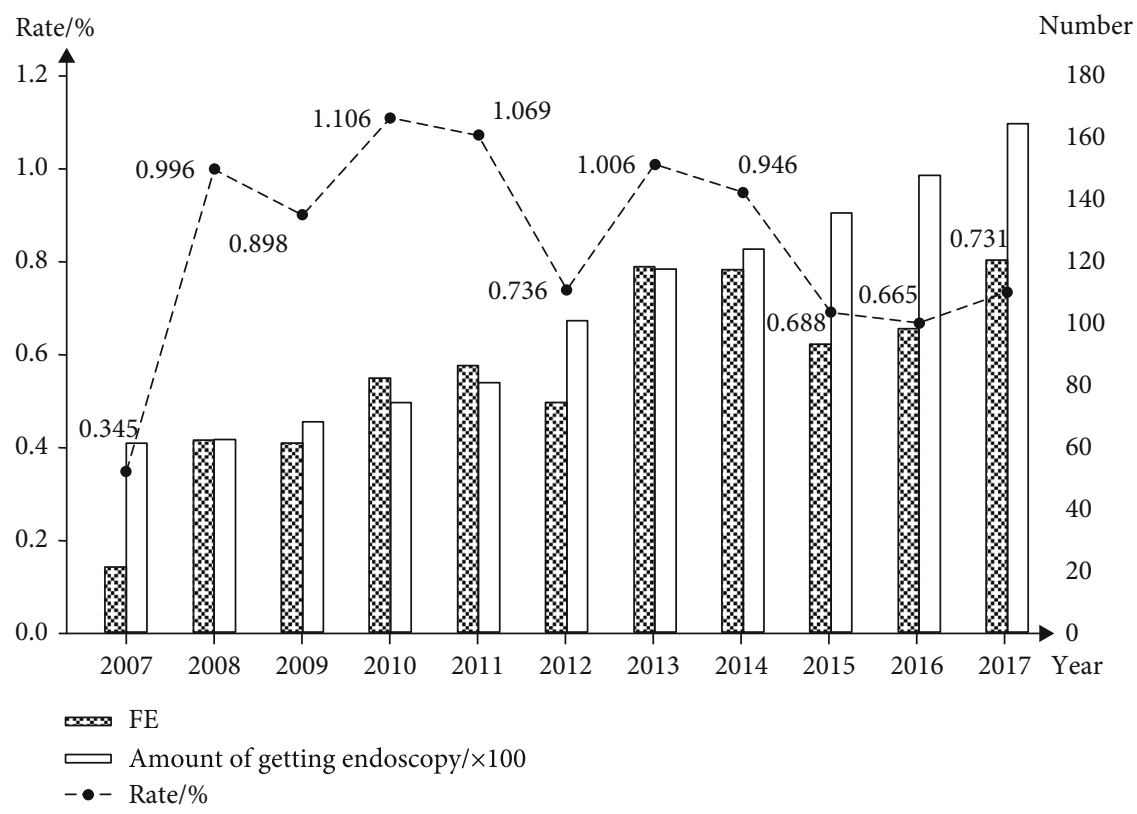

(a) Detection rate of FE from 2007 to 2017

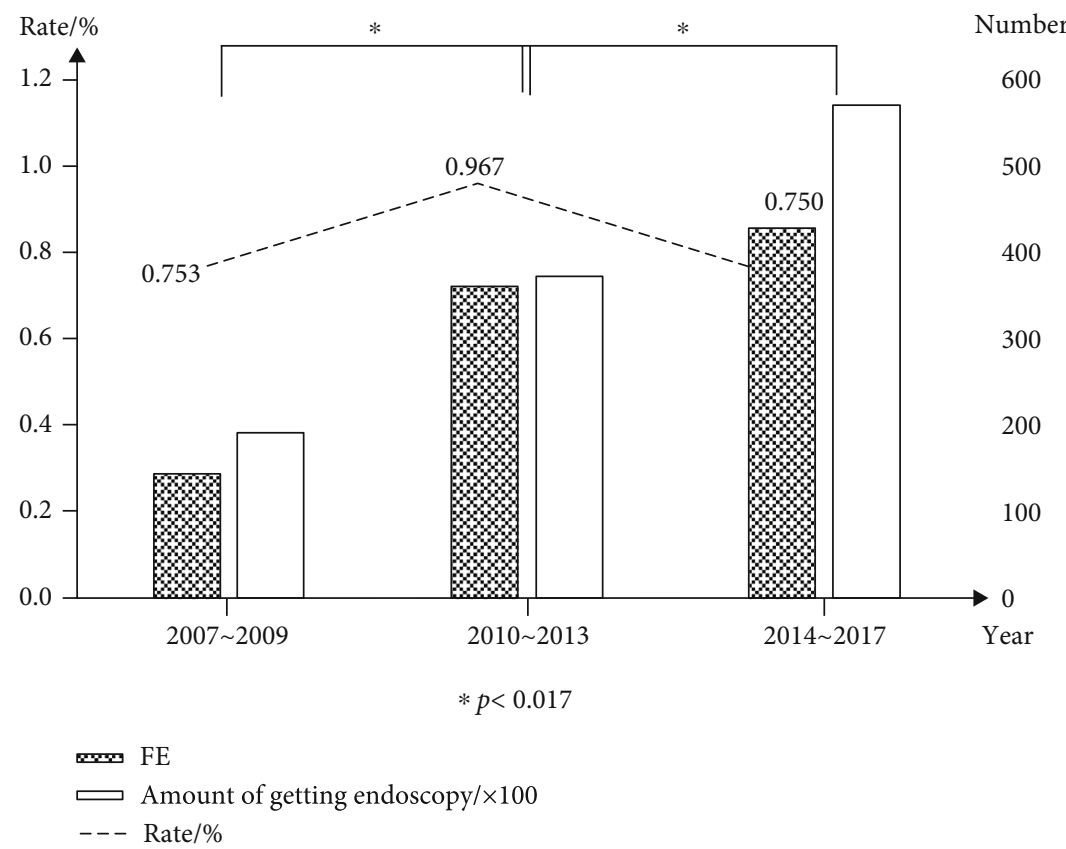

(b) Detection rates of FE in different time spans

Figure 1: Continued. 


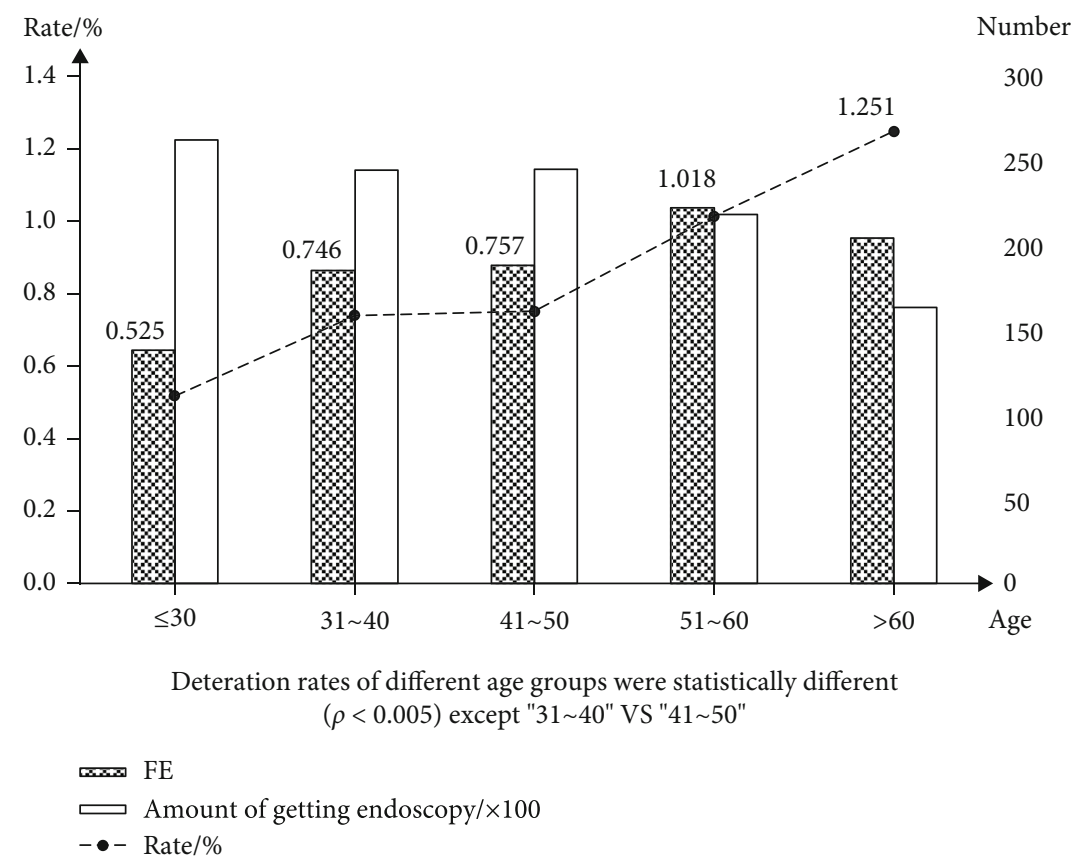

(c) Detection rates of FE in different age groups

FIgURE 1: Detection rates of FE in different time spans and age groups.

\section{Materials and Methods}

2.1. Patient Selection. The study was approved by the ethics committee of the Third Affiliated Hospital of Sun Yat-sen University and was in accordance with the later amendments of the 1964 Helsinki Declaration. Before the case-control study began, we explained the purpose of the analysis to the FE patients in person or over the telephone and asked for their permission to use their physical data; all patients signed a consent form. Patients who refused were excluded from the study. Informed consent was exempted by the ethics committee of the Third Affiliated Hospital of Sun Yat-sen University for the retrospective study.

The general information and endoscopic diagnosis of 113,390 patients treated in the endoscopy unit between January 2007 and December 2017 in the Third Affiliated Hospital of Sun Yat-sen University were reviewed. Among them, 932 patients were diagnosed with FE. General information such as age, sex, and therapy strategy, as well as therapeutic efficacy, was collected and confirmed by medical records.

To further understand the pathogen and risk factors for FE, a case-control analysis was conducted from August 2018 to February 2019. Whenever FE was diagnosed, two other participants whose numbers were next to the FE patient were randomly checked simultaneously; these participants were defined as controls. General information such as the age, sex, and clinical data of the patients and controls was collected through questionnaires. Finally, $101 \mathrm{FE}$ patients and 202 controls were enrolled after 9 patients and 18 controls were excluded for refusing or failing to complete the questionnaires. Each subject provided informed consent for participation in the study, and the research protocol was approved by the ethics committee of the Third Affiliated Hospital of Sun Yat-sen University.

2.2. Diagnosis of FE. The diagnosis of FE was made if white Candida plaques in the esophagus, as detected by endoscopy, could not be washed away, and fungal constituents, such as pseudohyphae or spores, were identified $[5,12]$. The severity was evaluated by Kodsi's classification [13]. Decreased severity after treatment was regarded as effective. Kodsi's grading was determined by two experienced endoscopic doctors who were blinded to all patient clinical information. Whenever they had different opinions, a conclusion was made by another senior doctor.

2.3. Questionnaires. We obtained clinical data through a questionnaire that included questions about symptoms; lifestyle habits, such as cigarette smoking; history of medication use (PPI use, corticosteroid or other immunosuppressant use, and antibiotic use); and history of chronic diseases, specifically HIV, diabetes, cirrhosis, and malignant tumors. Overall, $101 \mathrm{FE}$ patients and 202 controls completed the questionnaires in person or over the telephone.

The use of any PPI at a standard dose for at least 3 days was considered positive PPI use [14]. Similarly, the use of antibiotics for 3 days or a glucocorticoid at a dose equal to prednisone $20 \mathrm{mg}$ was considered positive antibiotics or glucocorticoid use, respectively [11]. A patient with any history of smoking was regarded as a smoker [15].

2.4. Fungal Culture and Drug Sensitivity. Samples of white esophageal plaques were collected from 55 FE patients; the samples underwent fungal culture and type identification. 
TABLE 1: Characteristics of FE patients and controls.

\begin{tabular}{|c|c|}
\hline Characteristics & $n=303$ \\
\hline \multicolumn{2}{|l|}{ Sex, n (\%) } \\
\hline Male & $183(60.4)$ \\
\hline Female & $120(39.6)$ \\
\hline \multicolumn{2}{|l|}{ Age, n (\%) } \\
\hline$\leq 30$ & $57(18.8)$ \\
\hline $31 \sim 40$ & $65(21.4)$ \\
\hline $41 \sim 50$ & $72(23.8)$ \\
\hline $51 \sim 60$ & $53(17.5)$ \\
\hline$>60$ & $56(18.5)$ \\
\hline \multicolumn{2}{|l|}{ Comorbidities, n (\%) } \\
\hline Esophageal varices & $40(13.2)$ \\
\hline Esophageal polyps & $10(3.3)$ \\
\hline Bile reflux & $11(3.6)$ \\
\hline Reflux esophagitis & $20(6.6)$ \\
\hline $\mathrm{HBV}$ & $48(15.8)$ \\
\hline Cirrhosis & $43(14.2)$ \\
\hline Diabetes & $23(7.6)$ \\
\hline HBP & $32(10.6)$ \\
\hline Malignant tumor & $26(8.6)$ \\
\hline \multicolumn{2}{|l|}{ Symptoms, n (\%) } \\
\hline Epigastric pain & $88(29.0)$ \\
\hline Chest tightness & $19(6.3)$ \\
\hline Acid regurgitation & $32(10.6)$ \\
\hline Belching & $30(9.9)$ \\
\hline Heartburn & $13(4.3)$ \\
\hline $\mathrm{AD}$ & $58(19.1)$ \\
\hline Nausea & $22(7.3)$ \\
\hline Vomiting & $15(5.0)$ \\
\hline Hiccups & $11(3.6)$ \\
\hline Globus sensation & $33(10.9)$ \\
\hline \multicolumn{2}{|c|}{ Previous medication, $\mathrm{n}(\%)$} \\
\hline Antibiotics & $53(17.5)$ \\
\hline PPI & $94(31.0)$ \\
\hline IS & $11(3.6)$ \\
\hline Smoking & $79(26.1)$ \\
\hline
\end{tabular}

HBV: hepatitis B virus; HBP: high blood pressure; AD: abdominal distention; PPI: proton-pump inhibitor; IS: immunosuppressant.

The antifungal sensitivity of yeast pathogens was determined. At least two samples from every FE patient were taken with a disposable cytology brush (Alton, China) for analysis. The specimens were transferred to two Sabouraud glucose agar plates (Caring, China) and incubated at $28^{\circ} \mathrm{C}$ and $35^{\circ} \mathrm{C}$ simultaneously. Then, we identified Candida, filamentous or diphasic fungi after 24, 48, and 72 hours, respectively, according to the color and shape of the colony on the agar. When Candida was identified, the colony was transplanted to CHROMagar (Caring, China) to further confirm the subtype, as different Candida strains display different colors. The Candida colony was put into $0.85 \%$ saline, and an antimicro-
TABle 2: Comparison of the clinical characteristics between FE patients and controls.

\begin{tabular}{|c|c|c|c|c|c|}
\hline \multirow[t]{2}{*}{ Clinical characteristics } & \multicolumn{2}{|c|}{$\begin{array}{l}\text { Controls } \\
(N=202)\end{array}$} & \multicolumn{2}{|c|}{$\begin{array}{c}\mathrm{FE} \\
\text { patients } \\
(N=101)\end{array}$} & \multirow[t]{2}{*}{$P$ value } \\
\hline & $n$ & $\%$ & $n$ & $\%$ & \\
\hline Sex, male & 112 & 55.4 & 71 & 70.3 & 0.01 \\
\hline \multicolumn{6}{|l|}{ Comorbidities } \\
\hline Esophageal varices & 28 & 13.9 & 12 & 11.9 & 0.63 \\
\hline $\mathrm{EP}$ & 3 & 1.5 & 7 & 6.9 & 0.03 \\
\hline Bile reflux & 10 & 5.0 & 1 & 1.0 & 0.16 \\
\hline Reflux esophagitis & 14 & 6.9 & 6 & 5.9 & 0.74 \\
\hline $\mathrm{HBV}$ & 31 & 15.3 & 17 & 16.8 & 0.74 \\
\hline Cirrhosis & 29 & 14.4 & 14 & 13.9 & 0.91 \\
\hline Diabetes & 12 & 5.9 & 11 & 10.9 & 0.13 \\
\hline HBP & 18 & 8.9 & 14 & 13.9 & 0.19 \\
\hline Malignant tumor & 10 & 5.0 & 16 & 15.5 & $<0.01$ \\
\hline \multicolumn{6}{|l|}{ Symptoms } \\
\hline Epigastric pain & 68 & 33.7 & 20 & 19.8 & 0.01 \\
\hline Chest tightness & 13 & 6.4 & 6 & 5.9 & 0.87 \\
\hline Acid regurgitation & 23 & 11.4 & 9 & 8.9 & 0.51 \\
\hline Belching & 22 & 10.9 & 8 & 7.9 & 0.41 \\
\hline Heart burn & 9 & 4.5 & 4 & 4.0 & 1.00 \\
\hline $\mathrm{AD}$ & 35 & 17.3 & 23 & 22.8 & 0.26 \\
\hline Nausea & 13 & 6.4 & 9 & 8.9 & 0.43 \\
\hline Vomiting & 8 & 4.0 & 7 & 6.9 & 0.26 \\
\hline Hiccup & 8 & 4.0 & 3 & 3.0 & 0.91 \\
\hline Globus sensation & 11 & 5.4 & 22 & 21.8 & $<0.01$ \\
\hline \multicolumn{6}{|l|}{ Previous medication } \\
\hline Antibiotics & 27 & 13.4 & 26 & 25.7 & 0.01 \\
\hline PPI & 65 & 32.2 & 29 & 28.7 & 0.54 \\
\hline IS & 2 & 1.0 & 9 & 8.9 & $<0.01$ \\
\hline Smoking & 40 & 19.8 & 39 & 38.6 & $<0.01$ \\
\hline
\end{tabular}

EP: esophageal polyps; HBV: hepatitis B virus; HBP: high blood pressure; AD: abdominal distention; PPI: proton-pump inhibitor; IS: immunosuppressants.

bial sensitivity test was performed with the ATB FUNGUS 3 method (bioMerieux S. A., France).

2.5. Statistical Analysis. The quantitative variable is presented as the median. For the comparison of qualitative data, such as the detection rate and clinical manifestations of FE, chisquare tests were performed. To analyze the associations, the Spearman rank correlation coefficient was calculated for ordinal variables, including the age group in the exploration of risk factors and the age stratification, initial disease severity, and recheck time period in the evaluation of therapeutic efficacy. For the multivariable analysis, a multiple logistic regression model was used to identify the different factors contributing to $\mathrm{FE}$ and therapeutic efficacy. The odds ratio (OR) and 95\% CI were estimated. Two-tailed $P$ values $<0.05$ were considered statistically significant. All analyses were conducted with the SPSS 20.0 software package (SPSS, Inc., Chicago, IL, USA). 
TABLE 3: Univariate and multivariate regression analyses of the factors related to FE.

\begin{tabular}{|c|c|c|c|c|}
\hline \multirow{2}{*}{ Variables } & \multicolumn{2}{|c|}{ Univariate analysis } & \multicolumn{2}{|c|}{ Multivariate analysis } \\
\hline & Odds ratio (95\% CI) & $P$ value & Odds ratio $(95 \% \mathrm{CI})$ & $P$ value \\
\hline Sex, male & $1.755(1.054,2.921)$ & 0.031 & & \\
\hline Age group & & & & 0.018 \\
\hline$\leq 30$ & $0.184(0.078,0.436)$ & 0.000 & $0.203(0.077,0.535)$ & 0.001 \\
\hline $31 \sim 40$ & $0.385(0.183,0.810)$ & 0.012 & $0.410(0.177,0.953)$ & 0.038 \\
\hline $41 \sim 50$ & $0.407(0.198,0.837)$ & 0.015 & $0.388(0.173,0.870)$ & 0.022 \\
\hline $51 \sim 60$ & $0.446(0.206,0.966)$ & 0.041 & $0.354(0.143,0.873)$ & 0.024 \\
\hline$>60$ & 1 (ref) & & & \\
\hline Symptom of globus sensation & $4.835(2.239,10.441)$ & 0.000 & $7.507(3.156,17.860)$ & 0.000 \\
\hline Symptom of epigastric pain & $2.055(1.163,3.633)$ & 0.013 & & \\
\hline Comorbidity of EP & $4.940(1.249,19.529)$ & 0.023 & $8.732(2.006,38.013)$ & 0.004 \\
\hline Comorbidity of diabetes & $1.935(0.822,4.554)$ & 0.130 & & \\
\hline Comorbidity of malignancy & $3.614(1.575,8.291)$ & 0.002 & $4.031(1.562,10.407)$ & 0.004 \\
\hline History of IS use & $9.783(2.072,46.180)$ & 0.004 & $6.525(1.089,39.105)$ & 0.040 \\
\hline History of antibiotic use & $2.247(1.230,4.105)$ & 0.008 & $2.178(1.078,4.400)$ & 0.030 \\
\hline Smoking & $2.548(1.500,4.325)$ & 0.001 & $3.017(1.645,5.533)$ & 0.000 \\
\hline
\end{tabular}

EP: esophageal polyps; IS: immunosuppressant.

\section{Results}

3.1. Detection Rate. From January 2007 to December 2017, 113,390 patients underwent gastroscopic examinations, among which 932 were diagnosed with FE. The overall detection rate of $\mathrm{FE}$ was $0.82 \%$. The detection rate in each year ranged from $0.35 \%$ to $1.11 \%$ (Figure $1(\mathrm{a})$ ). The highest rates were between 2010 and 2013; however, the rates decreased in the last 4 years (2007 2009 vs. 2010 2013: $\chi^{2}=6.478, P=$ 0.011; 2010 2013 vs. 2014 2017: $\left.\chi^{2}=12.727, P<0.001\right)$ (Figure 1(b)). Regarding sex, males seemed to be more susceptible to FE $(615 / 932,65.99 \%)$. The detection rate in males, which reached $1.0 \%$, was higher than that in females, which was only $0.6 \%\left(\chi^{2}=48.97, P<0.001\right)$. The median age of FE patients was 49 years old (range from 8 to 85 ). Among the different age groups, the detection rates varied, ranging from $0.55 \%$ to $1.25 \%\left(\chi^{2}=78.229, P<0.001\right)$. Similar to other infectious diseases, elderly individuals were more susceptible to FE than young individuals. The detection rate in people over 60 years old was higher than those in the age groups of 31 40 and 41 50 years old, while it was lowest in the group under 30 years old (Figure 1(c)).

\section{Clinical Manifestations and Risk Factors}

In the case-control study including $101 \mathrm{FE}$ patients and 202 controls, most of the FE patients were male (up to 70\%) (FE vs. controls: $\chi^{2}=6.48, P=0.012$ ), especially older males (FE vs. controls: Mann-Whitney $U=7547.0, P<$ 0.001). Regarding comorbidities, malignant tumor was more frequent in the $\mathrm{FE}$ patients than in the controls. Other comorbidities, such as HBV, cirrhosis, high blood pressure, and diabetes, were observed equally in both groups. Endoscopic comorbidities such as reflux esophagitis, bile reflux, esophageal varices, and esophageal polyps or papillomas were common. Among them, only esopha- geal polyps or papillomas were significantly different between the FE patients and controls; they were usually more common in the FE group.

Among all of the GI symptoms observed in the FE patients and controls, dysphagia and foreign body sensation were the most common in FE patients, while epigastric pain was the least common. Likewise, the ratio of smokers in the FE patient group was clearly higher than that in the control group. Moreover, the use of antibiotics or immunosuppressants seemed to contribute to FE. There was no significant difference in PPI use between the FE patients and controls (Tables 1 and 2).

A regression analysis was performed to analyze age; sex; smoking status; symptoms of dysphagia; globus sensations; epigastric pain; antibiotic use; immunosuppressant use; comorbidities of diabetes, malignant tumor, and esophageal polyps or papillomas; and FE incidence. As a result, increased age $(P=0.018)$, malignancy $(\mathrm{OR}=4.031,95 \%$ CI: $1.562 \sim 10.407)$, cigarette smoking $(\mathrm{OR}=3.017,95 \% \mathrm{CI}$ : $1.645 \sim 5.533$ ), and the use of antibiotics ( $\mathrm{OR}=2.178,95 \%$ CI: $1.078 \sim 4.400)$ or immunosuppressants (OR $=6.525$, 95\% CI:1.089 39.105) independently contributed to esophageal candidiasis. Esophageal polyps or papillomas $(\mathrm{OR}=$ 8.732, 95\% CI: 2.006 38.013) and a foreign sensation when swallowing were also associated with the disease $(\mathrm{OR}=$ 1.507, 95\% CI: 3.156 17.860) (Table 3).

\section{Pathogen Identification}

Samples of white esophageal plaques were collected from 55 FE patients from August to December 2018; the samples were subjected to fungal culture. Candida albicans was the causative agent for all 36 microbiologically confirmed cases. Specimen susceptibility testing against antifungal agents was performed. All of the specimens were 
TABle 4: Characteristics of the therapeutic cases.

\begin{tabular}{|c|c|}
\hline Characteristics & $n=157$ \\
\hline \multicolumn{2}{|l|}{ Sex, n (\%) } \\
\hline Male & $114(72.6)$ \\
\hline Female & $43(27.4)$ \\
\hline \multicolumn{2}{|l|}{ Age, n (\%) } \\
\hline$\leq 30$ & $15(9.6)$ \\
\hline $31 \sim 40$ & $23(14.6)$ \\
\hline $41 \sim 50$ & $36(22.9)$ \\
\hline $51 \sim 60$ & $47(29.9)$ \\
\hline$>60$ & $36(22.9)$ \\
\hline \multicolumn{2}{|l|}{ Initial severity, n (\%) } \\
\hline Kodsi 1 & $36(22.9)$ \\
\hline Kodsi 2 & $67(42.7)$ \\
\hline Kodsi 3 & $46(29.3)$ \\
\hline Kodsi 4 & $8(5.1)$ \\
\hline \multicolumn{2}{|l|}{ Location } \\
\hline Upper & $24(15.3)$ \\
\hline Middle & $15(9.6)$ \\
\hline Lower & $12(7.6)$ \\
\hline Upper and middle & $30(19.1)$ \\
\hline Lower and middle & $27(17.2)$ \\
\hline Upper and lower & $3(1.9)$ \\
\hline Whole & $46(29.3)$ \\
\hline \multicolumn{2}{|l|}{ Therapy strategy } \\
\hline Observation & $36(22.9)$ \\
\hline Nystatin & $54(34.4)$ \\
\hline Fluconazole & $57(36.3)$ \\
\hline Combination & $10(6.4)$ \\
\hline \multicolumn{2}{|l|}{ Recheck time } \\
\hline$<3$ months & $69(43.9)$ \\
\hline $3 \sim 6$ months & $24(15.3)$ \\
\hline $6 \sim 12$ months & $17(10.8)$ \\
\hline$>12$ months & $47(29.9)$ \\
\hline \multicolumn{2}{|l|}{ Therapeutic effect } \\
\hline Effective & $125(79.6)$ \\
\hline Ineffective & $32(20.4)$ \\
\hline
\end{tabular}

sensitive to 5-flurocytosine, amphotericin B, fluconazole, itraconazole, and voriconazole.

\section{Therapeutic Efficacy}

In total, 157 patients who underwent endoscopy were rechecked after their initial diagnosis of $\mathrm{FE}$ to evaluate the treatment effect. The data regarding general information and clinical characteristics, such as age groups or recheck times, were analyzed after every therapy cycle (Tables 4 and 5). In the regression analysis, age was found to have an effect on the therapeutic outcome $(P=0.026)$. After the modification of this factor, we found that fluconazole had a better curative effect than nystatin $(\mathrm{OR}=4.047$,
TABle 5: Comparison of the clinical characteristics between the effective and ineffective groups.

\begin{tabular}{|c|c|c|c|c|c|}
\hline \multirow[t]{2}{*}{ Clinical characteristic } & \multicolumn{2}{|c|}{$\begin{array}{c}\text { Effective } \\
(N=125)\end{array}$} & \multicolumn{2}{|c|}{$\begin{array}{l}\text { Ineffective } \\
(N=32)\end{array}$} & \multirow[t]{2}{*}{$P$ value } \\
\hline & $n$ & $\%$ & $n$ & $\%$ & \\
\hline Sex & & & & & 0.92 \\
\hline Male & 91 & 72.8 & 23 & 71.8 & \\
\hline Female & 34 & 27.2 & 9 & 28.2 & \\
\hline Age group & & & & & 0.07 \\
\hline$\leq 30$ & 13 & 10.4 & 2 & 6.2 & \\
\hline $31 \sim 40$ & 20 & 16.0 & 3 & 9.4 & \\
\hline $41 \sim 50$ & 33 & 26.4 & 3 & 9.4 & \\
\hline $51 \sim 60$ & 32 & 25.6 & 15 & 46.9 & \\
\hline$>60$ & 27 & 21.6 & 9 & 28.1 & \\
\hline Initial severity & & & & & 0.26 \\
\hline Kodsi 1 & 25 & 20.0 & 11 & 34.4 & \\
\hline Kodsi 2 & 53 & 42.4 & 14 & 43.7 & \\
\hline Kodsi 3 & 40 & 32.0 & 6 & 18.8 & \\
\hline Kodsi 4 & 7 & 5.6 & 1 & 3.1 & \\
\hline Location & & & & & 0.20 \\
\hline Upper & 19 & 15.2 & 5 & 15.6 & \\
\hline Middle & 12 & 9.6 & 3 & 9.4 & \\
\hline Lower & 10 & 8.0 & 2 & 6.2 & \\
\hline Upper and middle & 27 & 21.6 & 3 & 9.4 & \\
\hline Lower and middle & 24 & 19.2 & 3 & 9.4 & \\
\hline Upper and lower & 3 & 2.4 & 0 & 0 & \\
\hline Whole & 30 & 24.0 & 16 & 50 & \\
\hline Therapy strategy & & & & & 0.01 \\
\hline Observation & 23 & 18.4 & 13 & 40.6 & \\
\hline Nystatin & 41 & 32.8 & 13 & 40.6 & \\
\hline Fluconazole & 52 & 41.6 & 5 & 15.6 & \\
\hline Combination & 9 & 7.2 & 1 & 3.2 & \\
\hline Recheck time & & & & & 0.06 \\
\hline$<3$ months & 54 & 43.2 & 15 & 46.9 & \\
\hline $3 \sim 6$ months & 19 & 15.2 & 5 & 15.6 & \\
\hline $6 \sim 12$ months & 10 & 8.0 & 7 & 21.9 & \\
\hline$>12$ months & 42 & 33.6 & 5 & 15.6 & \\
\hline
\end{tabular}

95\% CI: $1.282 \sim 12.772)$ or simple observation $(\mathrm{OR}=8.91$, 95\% CI: 2.61 30.49). No significant difference was found between the nystatin and observation groups $(P=0.125)$ (Table 6).

\section{Discussion}

Little information about FE trends in China has been available in recent years. Here, we found that, over an almost 10-year period from 2007 to 2017, the detection rate of FE was $0.82 \%$, and the prevalence significantly increased. The highest prevalence occurred from 2010 to 2013 but decreased in the last 4 years. The FE prevalence in immunocompetent individuals has been reported $0.3-8.7 \%[4,8,16]$, which is consistent with our findings. The number of FE patients 
TABLE 6: Univariate and multivariate regression analyses of the factors related to therapeutic effectiveness.

\begin{tabular}{|c|c|c|c|c|}
\hline \multirow{2}{*}{ Variables } & \multicolumn{2}{|c|}{ Univariate analysis } & \multicolumn{2}{|c|}{ Multivariate analysis } \\
\hline & Odds ratio $(95 \% \mathrm{CI})$ & $P$ value & Odds ratio $(95 \% \mathrm{CI})$ & $P$ value \\
\hline Age stratification & & 0.091 & & 0.026 \\
\hline$\leq 30$ & $2.167(0.408,11.497)$ & 0.364 & $3.292(0.557,19.461)$ & 0.189 \\
\hline $31 \sim 40$ & $2.222(0.532,9.275)$ & 0.273 & $3.425(0.748,15.675)$ & 0.113 \\
\hline $41 \sim 50$ & $3.667(0.902,14.901)$ & 0.069 & $5.405(1.235,22.663)$ & 0.025 \\
\hline $51 \sim 60$ & $0.711(0.269,1.880)$ & 0.492 & $0.757(0.265,2.164)$ & 0.604 \\
\hline$>60$ & 1 (ref) & & 1 (ref) & \\
\hline Initial severity & & 0.263 & & \\
\hline Kodsi 1 & 1 (ref) & & & \\
\hline Kodsi 2 & $1.666(0.663,4.187)$ & 0.278 & & \\
\hline Kodsi 3 & $2.933(0.964,8.929)$ & 0.058 & & \\
\hline Kodsi 4 & $3.080(0.337,28.134)$ & 0.319 & & \\
\hline Therapy strategy & & 0.017 & & 0.004 \\
\hline Observation & 1 (ref) & & 1 (ref) & \\
\hline Nystatin & $1.783(0.708,4.486)$ & 0.220 & $2.202(0.802,6.043)$ & 0.125 \\
\hline Fluconazole & $5.878(1.876,18.421)$ & 0.002 & $8.912(2.605,30.490)$ & 0.000 \\
\hline Combination & $5.087(0.578,44.778)$ & 0.143 & $7.248(0.756,69.435)$ & 0.086 \\
\hline Recheck time & & 0.081 & & \\
\hline$<3$ months & 1 (ref) & & & \\
\hline $3 \sim 6$ months & $1.056(0.338,3.298)$ & 0.926 & & \\
\hline $6 \sim 12$ months & $0.397(0.129,1.219)$ & 0.107 & & \\
\hline$>12$ months & $2.333(0.785,6.936)$ & 0.127 & & \\
\hline
\end{tabular}

continued to increase because of the popularity of gastroendoscopy and the increasing number of people who underwent this type of exam. This reminds us of the importance of maintaining a focus on FE.

In this study, we found that elderly individuals accounted for a high proportion of FE patients. Increasing age is a risk factor for the onset of the disease, as well as an unfavorable factor for treatment. This may be caused by factors such as declining epithelial cell immunity in elderly people. Current research has confirmed that with increasing age, the number of $\mathrm{T}$ cells and $\mathrm{B}$ cells in the human body decreases, the antigen presentation ability of dendritic cells decreases, and both innate immunity and acquired immune function decrease $[12,17,18]$. Therefore, elderly people are susceptible to infectious diseases such as FE. In addition, older people often have multiple comorbidities and take combined medications, making the situation more complicated.

In our study, the proportion of patients who had dysphagia or foreign body sensation, which have been previously reported as typical presenting symptoms of FE, was significantly higher in the FE patient group than in the control group. Epigastric pain was more common in the control group than in the FE patient group. This is not surprising since epigastric pain is the most common complaint leading to endoscopy. For comorbidities, we found that malignant tumors were more frequent in FE patients than in control patients, while HBV, cirrhosis, high blood pressure, and diabetes were found equally in both groups. Thus far, there is concern that malignant tumors or chemotherapy will lead to immune suppression, resulting in Candida infection [19]. Additionally, since malignancy and infection share some common risk factors, such as comorbidities, lifestyle factors, and immune suppression, infection can be a risk factor for tumors [20].

Although many different studies have explored the risk factors of FE, only the effect of HIV infection, especially the decrease in CD4 + T lymphocytes $<200 / \mu$ l, has been consistently demonstrated [21, 22] [23]. Here, we found that the use of antibiotics or immunosuppressants independently contributed to esophageal candidiasis, which is in line with its nature as an opportunistic infection. Some prior studies have found that acid inhibitors, especially PPIs, are a risk factor for esophageal infection [24-27] due to fungal development in the stomach as well as the increase in gastric regurgitation $[28,29]$. In contrast, in our study, previous use of PPIs was not associated with FE. Consistent with our data, in a case-control study by Choi et al. and Takahashi et al., PPI use was not associated with FE $[9,11]$. However, the control group in our study was composed of patients with some gastrointestinal symptoms, such as epigastric pain. Therefore, most of them received PPI therapy; thus, unmeasured confounders might exist.

Notably, cigarette smoking was also a risk factor for FE in the multivariate analysis. To date, smoking has been demonstrated to disrupt the proliferation and transformation of immune cells and downregulate the secretion of cytokines, thereby inhibiting innate and adaptive immunity. This 
enhances the pathological inflammatory response and inhibits normal anti-infection immunity [30]. Abdelhabib et al. found that cigarette smoking directly increased the ability of membrane attachment and induced the formation of biological membranes in Candida albicans [31,32].

The comparison of different therapeutic strategies showed that fluconazole had a particularly positive effect on improving the esophageal appearance, while nystatin was also effective. Fluconazole at a dosage of 200 to $400 \mathrm{mg} / \mathrm{d}$ for 7 to 14 days is recommended for fungal infections by the guidelines in China, the United States, and Taiwan [22, 33-35]. Nystatin is reported to be effective at a dosage of 3 million U/d for 2 weeks [36, 37]. Nystatin acts by direct contact with the fungus and needs to be swallowed slowly after being dissolved in water; this process may reduce patient compliance. In the fungal culture and drug susceptibility tests of 36 patients, we found that Candida albicans was the causative agent, and all the specimens were sensitive to antifungal agents.

The study has the following limitations. In the retrospective case-control study, the information we collected was inevitably influenced by patients' unclear memory, tending to increase the risk of recall bias. In regard to the treatment effect evaluation, only patients with completed therapeutic information were included, resulting in the data loss of others who received therapy elsewhere or without reevaluation, likely increasing the risk of selection bias. As a study in a single-center, these results might elaborate only a single aspect of FE, and a well-designed multicenter study would be helpful to better understand this issue.

In conclusion, this study found that Candida albicans was the causative pathogen in patients with FE in South China, without apparent drug resistance. "Dysphagia" and "foreign body sensation" were the most common symptoms and had a certain suggestive effect for this disease. Increased age, smoking, and the use of antibiotics, corticosteroids, or immunosuppressive agents were independent risk factors for FE. Although fluconazole has a good therapeutic effect on fungal esophagitis, we still should pay more attention to FE treatment, given that individuals in today's rapidly aging society and elderly individuals tend to have comorbidities and take multiple drugs.

\section{Data Availability}

The datasets generated during the current study are available from the corresponding author on reasonable request.

\section{Conflicts of Interest}

The authors declare that there are no conflicts of interest regarding the publication of this paper.

\section{Acknowledgments}

This work was supported by the Basic Research Program of Young Teachers' Training Project of Sun Yat-Sen University (17ykpy52), but the work was independent of it.

\section{References}

[1] V. J. Anttila, P. Ruutu, S. Bondestam et al., "Hepatosplenic yeast infection in patients with acute leukemia: a diagnostic problem," Clinical Infectious Diseases : An Official Publication of the Infectious Diseases Society of America, vol. 18, no. 6, pp. 979-981, 1994.

[2] R. Kanzaki, M. Yano, K. Takachi et al., "Candida esophagitis complicated by an esophago-airway fistula: report of a case," Surgery today, vol. 39, no. 11, pp. 972-978, 2009.

[3] S. C. Mellinghoff, O. A. Cornely, and N. Jung, "Essentials in Candida bloodstream infection," Infection, vol. 46, no. 6, pp. 897-899, 2018.

[4] E. Karczewska, I. Wojtas, E. Sito et al., "Assessment of coexistence of Helicobacter pylori and Candida fungi in diseases of the upper gastrointestinal tract," Journal of Physiology and Pharmacology, vol. 60, Supplement 6, pp. 33-39, 2009.

[5] M. R. Onur, C. Aygun, M. Akyol, and H. I. Bahcecioglu, "Candida esophagitis mimicking esophageal carcinoma," The Turkish journal of gastroenterology : the official journal of Turkish Society of Gastroenterology, vol. 22, no. 6, pp. 648-649, 2011.

[6] S. Kuyumcu, Y. Sanli, G. Yegen, and A. Mudun, "Candida esophagitis mimicking esophageal malignancy on 18FDG PET/CT," The Turkish Journal of Gastroenterology, vol. 26, no. 1, pp. 63-64, 2015.

[7] M. Seong, T. W. Kang, and S. Y. Ha, "Pancreatic candidiasis that mimics a malignant pancreatic cystic tumor on magnetic resonance imaging: a case report in an immunocompetent patient," Korean journal of radiology, vol. 16, no. 6, pp. 1253-1256, 2015.

[8] J. Yakoob, W. Jafri, S. Abid et al., "Candidaesophagitis: risk factors in non-HIV population in Pakistan," World journal of gastroenterology, vol. 9, no. 10, pp. 2328-2331, 2003.

[9] J. H. Choi, C. G. Lee, Y. J. Lim, H. W. Kang, C. Y. Lim, and J. S. Choi, "Prevalence and risk factors of esophageal candidiasis in healthy individuals: a single center experience in Korea," Yonsei medical journal, vol. 54, no. 1, pp. 160-165, 2013.

[10] B. Kakati, A. Kotwal, D. Biswas, and S. Sahu, "Fluconazole resistant Candida oesophagitis in immunocompetent patients: is empirical therapy justifiable?," Journal of clinical and diagnostic research : JCDR, vol. 9, no. 12, 2015.

[11] Y. Takahashi, N. Nagata, T. Shimbo et al., "Long-Term Trends in Esophageal Candidiasis Prevalence and Associated Risk Factors with or without HIV Infection: Lessons from an Endoscopic Study of 80,219 Patients," PLOS ONE, vol. 10, no. 7, 2015.

[12] A. Rafi, S. C. Castle, K. Uyemura, and T. Makinodan, "Immune dysfunction in the elderly and its reversal by antihistamines," Biomedicine \& Pharmacotherapy, vol. 57, no. 5-6, pp. 246-250, 2003.

[13] N. Asayama, N. Nagata, T. Shimbo et al., "Relationship between clinical factors and severity of esophageal candidiasis according to Kodsi's classification," Diseases of the Esophagus, vol. 27, no. 3, pp. 214-219, 2014.

[14] J. M. Shin and N. Kim, "Pharmacokinetics and Pharmacodynamics of the Proton Pump Inhibitors," Journal of Neurogastroenterology and Motility, vol. 19, no. 1, pp. 25-35, 2013.

[15] J. Peto, "That the effects of smoking should be measured in pack-years: misconceptions 4," British journal of cancer, vol. 107, no. 3, pp. 406-407, 2012. 
[16] D. A. Kliemann, A. C. Pasqualotto, M. Falavigna, T. Giaretta, and L. C. Severo, "Candida esophagitis: species distribution and risk factors for infection," Revista do Instituto de Medicina Tropical de Sao Paulo, vol. 50, no. 5, pp. 261-263, 2008.

[17] K. Uyemura, S. C. Castle, and T. Makinodan, “The frail elderly: role of dendritic cells in the susceptibility of infection," Mechanisms of Ageing and Development, vol. 123, no. 8, pp. 955962, 2002.

[18] D. Weiskopf, B. Weinberger, and B. Grubeck-Loebenstein, "The aging of the immune system," Transplant International, vol. 22, no. 11, pp. 1041-1050, 2009.

[19] R. V. Lalla, F. I. Section, Oral Care Study Group et al., "A systematic review of oral fungal infections in patients receiving cancer therapy," Supportive care in cancer : official journal of the Multinational Association of Supportive Care in Cancer, vol. 18, no. 8, pp. 985-992, 2010.

[20] M. Norgaard, R. W. Thomsen, D. K. Farkas, M. F. Mogensen, and H. T. Sorensen, "Candida infection and cancer risk: a Danish nationwide cohort study," European journal of internal medicine, vol. 24, no. 5, pp. 451-455, 2013.

[21] N. Weerasuriya and J. Snape, "Oesophageal candidiasis in elderly patients: risk factors, prevention and management," Drugs \& aging, vol. 25, no. 2, pp. 119-130, 2008.

[22] S. Kohno, K. Tamura, Y. Niki et al., "Executive Summary of Japanese domestic guidelines for management of deep-seated mycosis 2014," Medical mycology journal, vol. 57, no. 4, pp. E117-E163, 2016.

[23] Y. Takahashi, N. Nagata, T. Shimbo et al., "Upper gastrointestinal symptoms predictive of Candida esophagitis and erosive esophagitis in HIV and non-HIV patients: an endoscopybased cross-sectional study of 6011 patients," Medicine, vol. 94, no. 47, p. e2138, 2015.

[24] A. Chocarro Martinez, F. Galindo Tobal, G. Ruiz-Irastorza et al., "Risk factors for esophageal candidiasis," European journal of clinical microbiology \& infectious diseases : official publication of the European Society of Clinical Microbiology, vol. 19, no. 2, pp. 96-100, 2000.

[25] J. A. Underwood, J. W. Williams, and R. F. Keate, "Clinical findings and risk factors for Candida esophagitis in outpatients," Diseases of the esophagus : official journal of the International Society for Diseases of the Esophagus, vol. 16, no. 2, pp. 66-69, 2003.

[26] K. Y. Kim, J. Y. Jang, J. W. Kim et al., “Acid suppression therapy as a risk factor for Candida esophagitis," Digestive diseases and sciences, vol. 58, no. 5, pp. 1282-1286, 2013.

[27] H. W. Daniell, "Acid suppressing therapy as a risk factor for Candida esophagitis," Diseases of the esophagus : official journal of the International Society for Diseases of the Esophagus, vol. 29, no. 5, pp. 479-483, 2016.

[28] S. B. Clayton, C. C. Rife, E. R. Singh, J. H. Kalbfleisch, and D. O. Castell, "Twice-daily proton pump inhibitor therapy does not decrease the frequency of reflux episodes during nocturnal recumbency in patients with refractory GERD: analysis of 200 patients using multichannel intraluminal impedance$\mathrm{pH}$ testing," Diseases of the Esophagus, vol. 25, no. 8, pp. 682-686, 2012.

[29] A. Wilson, J. Delport, and T. Ponich, "Candida glabrata Esophagitis: Are We Seeing the Emergence of a New AzoleResistant Pathogen?," International journal of microbiology, vol. 2014, Article ID 371631, 4 pages, 2014.
[30] F. Qiu, C. L. Liang, H. Liu et al., "Impacts of cigarette smoking on immune responsiveness: up and down or upside down?," Oncotarget, vol. 8, no. 1, pp. 268-284, 2017.

[31] H. Alanazi, A. Semlali, L. Perraud, W. Chmielewski, A. Zakrzewski, and M. Rouabhia, "Cigarette smoke-exposed Candida albicans increased chitin production and modulated human fibroblast cell responses," BioMed research international, vol. 2014, Article ID 963156, 11 pages, 2014.

[32] A. Semlali, K. Killer, H. Alanazi, W. Chmielewski, and M. Rouabhia, "Cigarette smoke condensate increases C. albicans adhesion, growth, biofilm formation, and EAP1, HWP1 and SAP2 gene expression," BMC microbiology, vol. 14, no. 1, p. 61, 2014.

[33] Infectious Diseases Society of Taiwan, Hematology Society of Taiwan, Taiwan Society of Pulmonary and Critical Care Medicine, Medical Foundation in Memory of Dr Deh-Lin Cheng, Foundation of Professor Wei-Chuan Hsieh for Infectious Diseases Research and Education, and CY Lee's Research Foundation for Pediatric Infectious Diseases and Vaccines, "Guidelines for the Use of Antifungal Agents in Patients with Invasive Fungal Infections in Taiwan - Revised 2009," Journal of Microbiology, Immunology and Infection, vol. 43, no. 3, pp. 258-263, 2010.

[34] P. G. Pappas, C. A. Kauffman, D. R. Andes et al., "Clinical practice guideline for the management of candidiasis: 2016 update by the Infectious Diseases Society of America," Clinical infectious diseases : an official publication of the Infectious Diseases Society of America, vol. 62, no. 4, pp. e1-e50, 2016.

[35] Association CM, "The diagnosis and treatment of Candidiasis: the expert consensus," Chinese Journal of Infection and Chemotherapy, vol. 11, p. 15, 2011.

[36] Y. L. Zhou, X. D. Wei, R. H. Mi et al., "A clinical study of fungal esophagitis in 13 patients with hematologic malignancies," Zhonghua xue ye xue za zhi = Zhonghua xueyexue zazhi, vol. 37, no. 6, pp. 507-511, 2016.

[37] S. Ebert, K. P. Schweiger, and R. Nau, "Candida esophagitis as the cause of swallowing disturbances in an 85-year-old patient with myasthenia gravis," Zeitschrift fur Gerontologie und Geriatrie, vol. 44, no. 4, pp. 268-269, 2011. 